\title{
Learning Management Systems, Social Programs and Their Effectiveness in E-Learning
}

\author{
Dr / Dalia Mohamed Nabil Tawfik Al.Sayed Al.Manhrawy \\ Assistant Professor - Department of tools and Techniques of Education- \\ Senior of unit E-learning and public relations - Faculty of Education - \\ University of Hail- Saudi Arabia \\ Dalia-tec@hotmail.com
}

\author{
Doi:10.5901/mjss.2013.v4n11p96
}

\section{Abstract}

Represents management systems learning (Learning Management systems) device used by most of the central institutions of higher education to support the educational process. And contrasts the performance of these systems with the increasing demand decentralization among Higher Education and Alhath, the use of open tools and services that contribute increasingly to promote a wide range of educational activities and practices outside institutional boundaries. With the proliferation of social networks (social networks) as one of the applications outstanding in the second generation of the Web (Web 2.0), called for the need to replace management systems traditional learning to other systems more open to keep up with the changes accelerated in web technologies and are consistent with the way the new generation with the network. Thus was born a new form of learning and management systems that combine the characteristics of traditional learning management systems and social networks. Of these modern systems site (schoology.com), which offers a free service for creating and managing learning systems, and mixing interface social networking with the management tools of learning, so that teachers and students (and parents and administrators) of communication and cooperation in educational matters. The site also provides educational traditional jobs in the months learning systems such as Blackboard and Moodle.

\section{Introduction}

There is a need for e-learning with the advent of the Internet, and have seen this technology in recent years A significant development with the evolution of the network itself. In the early Internet was the medium used in education Mail is limited to text only, but with the great technological development in Internet technologies have changed The traditional view of e-learning to turn to a more dynamic environments and inclusive. In addition, development Made in communication technology and the penetration of service fast Internet access via digital subscriber lines which will impact positively change the concept of e-learning and ways to display and interact with it to include, (DSL) high-speed 'new interactive aspects. This paper discusses a brief overview of the evolution of e-learning management systems, said the new trend in the transition. Followed by the definition of the concept of environments, (Personal Learning Environments) for personal learning environments Learning with your personal characteristics and benefits and how to create, and then the paper concludes by mentioning practical examples to develop Personal e-learning environments around the world.

\section{Known as e-learning}

Studied with educational materials that is easily accessible through the use of software for browsing, such as the Or by the Internet Explorer software program or Internet Explorer Netscape Netscape. (Especially (Khalifa, 2003 E-learning to the word, and that (e-learning) and that some professionals prefer the term translation Known as the "way to teach using the modern communication like the mechanisms, networks and media Multiple and online portals for the delivery of information to learners as soon as less expensive and more Enables management of the educational process and setup, measuring and evaluating the performance of learners.

E-learning is useful in several cases (Khalifa, 2003), including:

- support and complement traditional education.

- Teaching materials full - or to provide training in a timely manner.

- teach increasing numbers of students in crowded ranks. 
- The possibility of using the means at any time and any place.

Previous points (Learning Management Systems) and check most learning management systems mentioned, in addition to that they make it easier for the teacher and student communication process at any time, anytime. With the development of the Internet and the penetration of the Internet access service rapidly via digital subscriber lines high Change the concept of e-learning and ways to display and interact with it to include more aspects, (DSL) speed Which (E-Learning interactive, leading to the emergence of the so-called second generation of e-learning (2.0 And others in the process (Wikis) and wikis (Blogs) interested in employing social programs such as blogs Education.

\section{E-learning management systems}

And Learning Management systems (LMS) is intended to e-learning management systems Virtual Learning (VLE) sometimes called virtual learning environments That it had systems that work Kmsand and enhanced the educational process so that it lays teacher, EnvironmentsEducational materials from lectures and exams and sources in the system as there are rooms for discussion and portfolio And other electronic services subsidized school material. le (ePortfolios) for students' workLearning Management Systems are programs that help to store the content of courses electronically as it facilitates. Management of the learning process.

One of the characteristics of these programs includes.

- Publish and provide courses.

- Management of student records and follow-up activities.

- The possibility of communication between students and teachers through Dialogic Private forums.

- Publication of examinations and evaluation.

At present, there is a large amount of learning systems management programs where there are almost more than 200, (Course-centric) software package (Atmesa, 2006). These systems are based on the curriculum in the sense that all students enrolled in these systems will see the same approach and the same order and using the same Tools. These systems also come on the two types, some of which is free and open source programs such as Model. (Blackboard), including what is a commercial program such as Blackboard (Moodle) Learning management systems and virtual worlds Know virtual worlds on the programs they represent three-dimensional virtual environments can used for these worlds And also the construction and design of buildings and features and do (avatars) create virtual incarnation called figures Various types of activities. In these worlds can identify and communicate with other people from different parts of the world.

The most prominent virtual worlds on the Internet. This has hired (Second Life) is the world of Second Life In the world of education by many educational and academic institutions and even commercial, is added to that 2007).

The most prominent virtual worlds on the Internet. This has hired (Second Life) is the world of Second Life In the world of education by many educational and academic institutions and even commercial, is added to that 2007). For, Kapp) more than 70 educational institutions have established a presence in the world of Second Life Island building training in the world of Second Life with classes (Cisco), for example the Cisco On the same approach. The world (IBM) seminar to train employees in the company, followed by IBM Avatar Languages Second Life is used in the teaching of languages, where the school language teaching Using the default in the default language learning called (tasks surreal). "These functions combine language learning through Second Life and real life e-learning and sources of media-rich video and audio through the integration of Communication and curriculum based on the performance of the tasks "(Vickers, 2007). The addition of the world of Second Life to Features SOUND allows its members to speak with each other directly enabled teachers to provide more lessons Interactive. Learning management systems and social programs before recognize what are the social programs will give a simple overview of the second generation of Web 2.0. Characterized 'Web 2.0 interactive techniques, flexibility and effectiveness of the sensor can these techniques given in the examples of services (RSS) and extracts sites (weblogs) and blogs (wikis) provided by programs such as Wikis And others. Was the first appearance of the term Web 2.0 in 2005, and specifically in the conference of the same name. Brainstorming in a meeting which was held on the sidelines of the conference between each of the O'Reilly Company and : (Websites, services and applications where there is a number of characteristics, including (Khalifa, 2006

1. Provide a high degree of interactivity with the user: The this sense Interactive user when using A Web 2.0 applications like uses a desktop application on his machine.

2. User participation in content: Previously, the Web is a platform for read-only, the contact On the Web was edited by the people belonging to either the companies or universities or private institutions or Government, 
not the average user of the Internet is able to contribute to the content of the publication. At the present time It has become a user can add and modify the contents of the Web sites - that allow it - easily. Including that President nerve in Web 2.0 technologies are based on: (Tagging)

3. possibility characterization Content The existence and content contributed by the user, either directly or indirectly, it was necessary to find a way to help Also used on the labeling of any characterization of these contents to sort and arrange to return to it later andTake advantage of them.

On One of the characteristics of these programs include:

1. Publish and provide courses.

2. Management of student records and follow-up activities.

3. The possibility of communication between students and teachers through Dialogic Private forums.

4. Publication of examinations and evaluation.

As can be seen these systems as a set of tools (such as forums and examinations, etc.) And information (educational content and information and other students), which employs to serve a specific curriculum context.

\subsection{Generally there are close to each other concepts with some differences, including:}

\section{(CMS -Course Management System)}

(LMS - Learning Management System)

(LCMS - Learning Content Management System)

This is known as the gateway shortcut (Web CT), is a global system for the management of courses and educational materials based on the virtual environment that come online in the forefront, and produced by the company's global Blackboard, one of the largest companies specialized in the field of Learning Management Systems Learning Management System, and offers this product now under the name of Blackboard Learning System after the company Blackboard bought WebCT and is one of the most courses delivery systems prevalent especially in the field of higher education. Developed this system at the University of British Columbia and was soon adopted by several other universities around the world has evolved a system Web CT from being a system for providing educational materials via the Internet to the system for the management and delivery of educational materials such as authoring tools and electronic publishing as well as training services, counseling, and can refer to system on the Web site to identify the services, and if we reviewed the capabilities of the system based on the number of studies that addressed the analysis and the study found are summarized as follows:

1. Learning Tools: It consists of:

a. Meetings system, which is a newsletter Panel Bulletin Board.

b. E-mail.

c. Dialogue system (Conversation Chat).

d. Self-assessment tools for students.

e. A dictionary of terms can be connected with links within the context. And. The area where scholars presented their business.

f. Timed tests on-line Timed Online Quizzes.

g. External references.

h. Automated search within the content.

i. Learner's guide (for using the aid system).

2. And content display function: a hierarchical or linear manner, as well as the introduction to this content, and providing ultra links to other sites outside the system had the learner Alastzadh.

3. D function: It consists of a number of functions that help teachers develop their courses.

4. Teacher Tools: Special tools include follow-up to the learner to the location and movement behavior of students inside, as well as special programs authored tests.

\subsection{Examples of system tools City website:}

Curriculum content Content: Browse and save the educational content in decision Introduction Curriculum Syllabus: are recognized on a scheduled plan and its objectives and core subjects and his previous requirements are also the definition professor decision.

E-mail Mail: a special e-mail system to be students. 
Discussion forums Discussions: forum dialogue between students and between them and their teacher with regard to the decision.

Electronic whiteboard Whiteboard: These tool users can write or draw certain forms and viewed by other users. Duties and tasks Assignments: Through this tool Add the duty of the students are then delivered assignments in a timely manner.

\subsection{Tests Quiz: This tool provides the possibility of testing the student according to the given time.}

Calendar Calendar: This tool is available to identify information about the most important events during the course of rapid and effective.

Some of the main advantages of the Web City include the following:

- $\quad$ Ability to use multimedia.

- Self-assessment tools for students and immediate assessment tools.

- The organization and distribution of marks.

- Through the system can communicate conferences and communication between students, as well as between the student and the teacher.

- The advantage of being fragmented and conferences can be searched.

- E-mail system.

- The ability to search by the teacher.

- $\quad$ And effective links with the Internet.

- $\quad$ The ability to instant messaging in real-time time.

- Archived images are searchable.

- Exhibition space for students and create master pages.

- $\quad$ The ability to put notes on the page.

- A set of design and management tools.

- Security and access control.

- The ability to record and copy the lesson.

- Is a system of systems based on the icons in the sense that every function of previous jobs appear in front of the student in the form of a miniature called Icon Once you squeeze it begins to interact with that function.

- The system is compatible with all standard Internet browsers, the learner can also be used by either IBM or Mac system and this is independent of the working platform Platform Independent. The system offers a dual private first student interaction and display only the content and student tools, and the second a private designer and includes some special tools to design on-line and follow-up of students and edit their data and control what displays on each student.

\subsection{It can interface through students obtain the following information:}

1. Browse own lecture notes: To allow reviewing notes teachers in the classroom.

2. Billboard: a space that can be for students which the comment letters relating to the separation, and interaction with their colleagues. This area also includes the "Update News" where teachers announce updated information regarding the dismissal.

3. Test Messaging: Includes all of the tests and examinations, where tests are evaluated immediately upon completion, giving the brand directly to schools.

4. Curriculum: Includes curriculum prescribed by the teacher.

5. Homework: include homework and projects required by the teacher and allocated for the semester.

6. Tags: allow schools to examine the progress in the classroom and determine the current mark.

7. Events related article: Department of the agenda of the session includes the dates of the duties in the classroom and tests as well as scheduled events that are announced by the instructor.

8. Home pages for students: the system provides a mini home page for all students in the classroom.

\section{Blackboard system:}

Produced by Blackboard for educational services on-line, based in Washington, DC, and sees Richard F. Dragan 
Richard V. Dragan system that paved the way for institutions to raise their educational and training programs across networks. Comes the power of this system to provide a number of options to the user (the author of the program) to choose from what fits his need it provides library consisting of about one hundred of the buttons and templates, as well as the system provides tools allow the learner to interact with colleagues and make most of the network capabilities. On the other hand the system provides support for various file formats as MS Word program files and PDF file format for electronic publishing and sharing files across the network. In addition to the further advantage of providing a model for direct on-line test allows the teacher to design different types of tests. Blackboard system was marked for the rest of the systems that have been analyzed in that it offers a free copy of the teacher can be used to provide the course you want to put it on a direct line to be free of this decision and that the server is through the system. It also provides a guide to the use of the system on the internet, which shows the tools that can be included in the decision - all or some of them - so as to enable the learner to exercise various educational activities, and review this guide can select the following functions provided by the system:

1. Provide tools learner interaction: It means the tools that interact with the learner during the study are as follows:

A. Ads: allow this tool to schools latest news or notifications or declarations that he wants to send faculty members to learners or to a group of them and the student review by simply clicking pointer mouse key ads to show him the panel can list their content either alphabetically or historically.

B. Calendar: tell this tool learner Ptoukitat of the events related to the subject learning and Raise of when the time comes, such as lectures and meetings on the network or meetings and face-to-face university, etc., can be for the learner to add to what he wants from the events.

C. Tasks: tell the student what must play tasks, as it allows him to organize those tasks by subject or according to his personal vision, and the teacher can be sent to a particular learner a specific task not sent to another learner.

D. Estimates: This task Ptkadirath concerned both in the interim or final exams.

E. Users Manual: This tool guides the work of the students participating in the course to get to know each other.And. Address Book: The book is a personal student puts the data on those who want to communicate with them through the system, the user Vdleil former may include hundreds of students The Address Book fitted with the titles added by the student himself.

2. Show Content: The basic function of the system to provide educational materials is to provide educational material content to learners. In this regard the Blackboard system and content within the display function scheduled content option (Course Content) and when the student chooses this function the system will review the following content pictures:

A. Display text information accompanied by pictures and animated graphics and other elements, according to the organization educational organization required.

B. Documents and files related to the subject of study.

C. Books and references available on the network, or that the teacher advised his students read.

D. Links to important sites.

3. Contact function: system provides three ways to communicate between each other's students and between students and the teacher as follows: -

A. Send and receive e-mails, providing evidence of the names and mailing addresses of students referred to above.

B. Discussion boards Discussion Board: also called plate's ads Bulletin Board, one of the tools asynchronous interactions where the student can express his opinion on any issue or ask a question to be reviewed by peers later.

C. Chapter default Virtual Classroom: This label stands for network meetings on the system user to the system. This system allows the learner to dialogue with his colleagues and mentor what looked like Chapter default through the panel Chat Panel dialog box which enables the student to write what he wants through the keyboard to see all of the related meetings system at this time. It also allows a graphical panel like white Balsburh and movement of text or images, graphics, and presented to the students or the teacher.

And check most learning management systems Previous points Mentioned, as well as make it easier for the teacher and student communication process at any time, anytime. With the development of the Internet and the penetration of the Internet access service rapidly via digital subscriber lines high Change the concept of e-learning and 
ways to display and interact with it to include more aspects, (DSL) speed Which (E-Learning interactive, leading to the emergence of the so-called second generation of e-learning 2.0 And others in the process (Wikis) and wikis (Blogs) interested in employing social programs such as blogs Education. "Interested in supporting the social aspect of the educational process in compensation for spatial separation between the teacher and the learners And through the use of social software (software that enhance the partnership and communication between Learners), such as blogs, wikis, and the formation of communities of learners, voice broadcast and transmit video And social networks. The exchange of links to the Web through labeling programs the important links helps to know the learner to others with a similar interest"

\subsection{Learning management systems and social programs}

Before recognize what are the social programs will give a simple overview of the second generation of Web 2.0. Characterized

Web 2.0 interactive techniques, flexibility and effectiveness of the sensor can these techniques given in the examples of services (RSS) and extracts sites (weblogs) and blogs (wikis) provided by programs such as Wikis And others. Was the first appearance of the term Web 2.0 in 2005, and specifically in the conference of the same name

Brainstorming in a meeting which was held on the sidelines of the conference between each of the O'Reilly Company and : (Websites, services and applications where there is a number of characteristics, including (Khalifa, 2006

1. Provide a high degree of interactivity with the user: The this sense Interactive user when using A Web 2.0 applications like uses a desktop application on his machine.

2. User participation in content: Previously, the Web is a platform for read-only,the contact On the Web was edited by the people belonging to either the companies or universities or private institutions or Government, not the average user of the Internet is able to contribute to the content of the publication. At the present time It has become a user can add and modify the contents of the Web sites - that allow it - easily. As the nerve President in the techniques of Web 2.0 is based on the presence of content and which contributed to its user, either directly or indirectly, it was necessary to find a way to help the user also labeling (ie, characterization) of these contents to sort and arrange to return to it later and take advantage of them. As applications connect people to each other (social software) know social programs to store and organize del.icio.us benefit from the exchange of experiences and ideas, examples of these applications for the storage site and YouTube video sharing to store and organize your images, and Flickr links, and site Blogs and wikis, and others. We find that learning management systems did not keep pace quickly spread and acceptance of social programs to the people as we find few Of these systems from the integration of property or more of the characteristics of social programs in their systems, resulting in To the reluctance of some learners from the use of such systems, systems thinking and alternative environments provide them with education According to personal needs. This change in the Web has led to the emergence of the concept of e-learning environments Personal - as will be mentioned later - which centered on applications to take advantage of the second generation of the Web And customized to serve.

\section{Problem of the study}

Of the problems faced by the institutions of education and vocational training as follows:

1. multiplicity of supervising and implementing education programs and vocational training

2. the inadequacy of educational programs to the needs of the labor market, ineffective

3. leakage in all stages of education

4. weak cooperation between education institutions and vocational training and labor market institutions

5. the inadequacy of current patterns of education and diversity

6. double the funding process.

7. Management.

\section{Objectives of the study}

Released e-learning to reduce the administrative burden that she was taking me to a great time in each lecture such as receipt of duties, etc., it has become possible to send and receive via electronic gadgets with the possibility of knowledge of receipt of the student to these documents and the commitment of the student handed in a specific time also provided 
e-learning assessment tools Messaging and give the teacher a variety of ways to build a distribution and classification of information in a quick and easy way to assess At the level of my students has touched the following benefits: -

1. increase the possibility of communication between students scheduled among themselves and no longer confined to their meeting in the traditional classroom through the ease of communication among themselves in several directions, such as discussion boards, e-mail, chat rooms. Adding to motivate them to participate and interact., And through personal experience occurred by chance in one of the courses where I had agreed with the students to meet with them to answer their questions through Elluminate Live occurred exigent circumstances delayed the date of the meeting, about half an hour, and when I entered and found the students discuss in the decision and some of them explain the parts of the decision and I learned after he left them sat for at least an hour and a half complete their discussion.

2. To contribute to the different viewpoints of students: Forums instant such as discussion boards and chat rooms provide opportunities for the exchange of views on the topics which increases opportunities to take advantage of the views and proposals and merged with the views of the student, which helps in the formation of a solid foundation when the learner is composed has knowledge and strong opinions The sound through the acquired knowledge and skills through chat room.

3. Were made available to each student the opportunity to make his opinion at any time and without embarrassment, as opposed to the classroom traditional deprive him of this feature, either because of poor organization of the seats, or weak voice student himself, or shame, or other reasons, and through learning was given full opportunity for the student to send his opinion through the available communication tools such as e-mail and discussion boards and chat rooms. I recall here the experience of the decision of the translators where I established the Council discussion under the title questions and suggestions about the decision translators and through this Council received many useful suggestions in the course and Adha Some students develop programs to help them to understand the solutions some of the issues and the others summarized parts of the decision and posed to his colleagues, some of whom he resolved some issues and examples, and so is worth mentioning I deliberately to join the the Council of the discussion of the faithful to the students of the current chapter to be an incentive for them to actively participate

4. that e-learning allows students easy access to teacher scientific material and great ease to access it quickly and outside official working hours, because the student has become able to send inquiries through the website of the decision, and this feature is useful and appropriate also for the teacher to respond to inquiries at any time It is anywhere

5. e-learning allowed the students to focus on important ideas during the writing and assembled for a lecture or lesson, and also allows students who have difficulty focusing and organizing tasks benefit from the article because they are arranged and coordinated manner easy and good and important elements of the specific They can also listen to lectures recorded several times.

6. Provides scheduled $24 / 7$ all day and every day of the week ( 24 hours a day, 7 days a week this feature reported students who want education in a given time am or pm, as well as for those who bear the burdens and responsibilities of personal, this feature allows for all learning.

\section{Study Methodology}

Using the current study "descriptive analytical approach" which is "a curriculum that cares about what is an object and interpreted and work to identify the relationships between reality and expectations and different directions along the comparison and description," The researcher used this approach to shed light on the importance of good quality in elearning as well as the procedures and processes specific set by distance education institutions to organize their administration and provide services in accordance with the requirements of the labor market and evaluate the output of this type of education. And Derive sources and writings that were discussed this subject and the conclusions reached by the researcher to develop solutions to secretions and the repercussions of this problem.

\section{References:}

Khalifa, India girl Suleiman (2003). Recent trends and developments in the study of e-learning service Comparison of the four models of distance education. School of the Future Symposium. College of Education - King Saud University.

Khalifa, India girl Suleiman (2006). Employ Web 2.0 technologies in the service of education and training-mail. Fourth Saudi Technical Conference for vocational training and technical support. Riyadh. Kingdom of Saudi Arabia. 
The Egyptian National Center for e-learning. (2008), Introduction to e-learning. Available on the Internet http://www.nelc.edu.eg/arabic/introduction_elearning/topic8.php

Atmesa, Jamil Ahmed Salim (2006). Flexible system for the management of e-learning in order to support education in Traditional universities and open. Available on the Internet http://etsiit.ugr.es/usuarios/jamil/abs.htm

Vickers, Howard. (2007). New techniques in language teaching integrate virtual worlds with real-life (article Translated). Available on the Internet http://www.saidaonline.com/news.php?go=fullnews\&newsid=178

Wilson, S, Beauvoir, P, Milligan, C, Sharples, P, Johnson, M.W. \& Liber, O. (2006) "Challenging the dominant design of educational Systems" - ECTEL Conference, Crete, 2006.

Olivier, Bill, \& Liber, Oleg. (2001) Lifelong Learning: The Need for Portable Personal Learning Environments and Supporting Interoperability Standards. The JISC Centre for Educational Technology Interoperability Standards, Bolton Institute December 2001.

Karl M. Kapp. (2007). Defining and Understanding Virtual Worlds. Available online http://www.learningcircuits.org/2007/0507kapp.htm

Mike Macedonia, (2007). "Generation 3D: Living in Virtual Worlds," Computer, vol. 40, no. 10, pp. 99-101.

Dalsgaard, Christian (2006).Social software: E-Learning beyond learning management systems.European Journal of Open, Distance and E-Learning, 2006-07-12

Livingstone, Daniel, Ed.; Kemp, Jeremy, Ed. (2006). Putting a second life "metaverse" skin on learning management systems. Proceedings of the Second Life Education Workshop, Part of the Second Life Community Convention (1st, San Francisco,

California, August 18-20, 2006).Downes, Stephen (2005). E-learning 2.0. Retrieved April 22, 2008, from http://www.elearnmag.org/subpage.cfm?section=articles\&article=29-1

Sean FitzGerald. (2006). Creating your Personal Learning Environment. Retrieved April 22, 2008, from http://seanfitz.wikispaces.com/creatingyourple

Wikibooks. (2008). Why PLE? Retrieved April 22, 2008, from http://en.wikibooks.org/wiki/Literature_reviews_of_PLE 